OPEN ACCESS

Edited by:

Dake Xu,

Northeastern University, China

Reviewed by:

Ru Jia,

Texas A\&M University, United States

Tao Liu,

Shanghai Maritime University, China

*Correspondence:

Guangzhou Liu

liuguangzhou@sdu.edu.cn

Dun Zhang

zhangdun@qdio.ac.cn

Specialty section:

This article was submitted to

Microbiological Chemistry

and Geomicrobiology,

a section of the journal

Frontiers in Microbiology

Received: 16 February 2019

Accepted: 12 April 2019

Published: 08 May 2019

Citation:

Chen S, Deng H, Liu G and

Zhang D (2019) Corrosion of Q235

Carbon Steel in Seawater Containing

Mariprofundus ferrooxydans

and Thalassospira sp.

Front. Microbiol. 10:936.

doi: 10.3389/fmicb.2019.00936

\section{Corrosion of Q235 Carbon Steel in Seawater Containing Mariprofundus ferrooxydans and Thalassospira sp.}

\author{
Shiqiang Chen ${ }^{1,2,3}$, Hao Deng ${ }^{1}$, Guangzhou Liu ${ }^{1 *}$ and Dun Zhang ${ }^{2,3 *}$ \\ ${ }^{1}$ Institute of Marine Science and Technology, Shandong University, Qingdao, China, ${ }^{2}$ Key Laboratory of Marine \\ Environmental Corrosion and Bio-fouling, Institute of Oceanology, Chinese Academy of Sciences, Qingdao, China, ${ }^{3}$ Open \\ Studio for Marine Corrosion and Protection, Qingdao National Laboratory for Marine Science and Technology, \\ Qingdao, China
}

Iron-oxidizing bacteria (IOB) and iron-reducing bacteria (IRB) can easily adhere onto carbon steel surface to form biofilm and affect corrosion processes. However, the mechanism of mixed consortium induced carbon steel corrosion is relatively underexplored. In this paper, the adsorptions of IOB (Mariprofundus ferrooxydans, M. f.), IRB (Thalassospira sp., T. sp.) and mixed consortium (M. f. and T. sp.) on surface of Q235 carbon steel and their effects on corrosion in seawater were investigated through surface analysis techniques and electrochemical methods. Results showed that local adhesion is a typical characteristic for biofilm on surface of Q235 carbon steel in M. f. and mixed consortium media, which induces localized corrosion of Q235 carbon steel. Corrosion rates of Q235 carbon steel in different culture media decrease in the order: $r_{M . f .}>r_{\text {mixed consortium }}>r_{T}$. sp. $>r_{\text {sterile. }}$ The evolution of corrosion rate along with time decreases in M. f. medium, and increases then keeps table in both T. sp. and mixed consortium media. Corrosion mechanism of Q235 carbon steel in mixed consortium medium is discussed through analysis of surface morphology and composition, environmental parameter, and electrochemical behavior.

Keywords: Q235 carbon steel, EIS, SEM, XPS, microbiologically influenced corrosion

\section{INTRODUCTION}

Carbon steel, as a common material in marine engineering, is vulnerable to corrosion. Microorganisms is one of the significant factors affected the metal corrosion process in marine environment, i.e., more than $20 \%$ of corrosion related failures are attributed directly or indirectly to microbiologically influenced corrosion (MIC) (Bhandari et al., 2015). Among the corrosive microbes, iron reducing bacteria (IRB) and oxidizing bacteria (IOB) are two kinds of special microorganisms using iron as an electron acceptor and donor, respectively, (Byrne et al., 2015). IRB combine reduction of $\mathrm{Fe}$ (III) with oxidation of organic matter or $\mathrm{H}_{2}$ for energy conservation, i.e., IRB readily use dissolved Fe(III) complexes or short-range-ordered minerals (e.g., ferrihydrite) and even magnetite as terminal electron acceptors (Pan et al., 2017; Fortney et al., 2018). IOB grow with $\mathrm{Fe}(\mathrm{II})$ or $\mathrm{H}_{2}$ as the electron donor coupled to the reduction of oxygen in environments at acidic and circumneutral pH values (Weber et al., 2006; McBeth and Emerson, 2016). In marine environment, 
$\mathrm{Fe}^{2+}$ and $\mathrm{Fe}^{3+}$ compounds, i.e., $\mathrm{Fe}_{3} \mathrm{O}_{4}, \mathrm{FeOOH}, \mathrm{Fe}_{2} \mathrm{O}_{3}, \mathrm{FeS}$, etc., are widely distributed, especially for around the marine engineering material based on steel (Qian et al., 2018; Chen and Zhang, 2019), which provides favorable conditions for the survival of these two bacteria. Meanwhile, they can easily adhere onto steel surface to form biofilm and affect corrosion processes (Wang et al., 2012; Li et al., 2016).

Mechanisms of IOB or IRB induced corrosion have been extensively studied. IOB could produce dense deposits made up of intact and/or the partly degraded remains of bacterial cells mixed with amorphous hydrous ferric oxides/hydroxides, which resulted in a crevice effect and induced pitting corrosion of stainless steel (Xu et al., 2007; Starosvetsky et al., 2008; Lee et al., 2013). Additionally, corrosion of carbon steel was promoted due to that $\mathrm{Fe}^{3+}$ produced from IOB metabolism can rapidly oxidize $\mathrm{Fe}^{0}$ to $\mathrm{Fe}^{2+}$ (Wang et al., 2014; Liu et al., 2016; Liu H. et al., 2018). The relationship of IRB to corrosion was not straightforward, i.e., IRB may enhance corrosion under some circumstances, or have a passivating effect on corrosion in others (Duan et al., 2008; Mehanna et al., 2008; Esnault et al., 2011; Schutz et al., 2014, 2015; Cote et al., 2015; Starosvetsky et al., 2016). Corrosion acceleration induced by IRB was mainly related to that the reduction of insoluble ferric compounds to soluble ferrous ion facilitated the removal of protective corrosion products on steel surface (Esnault et al., 2011; Starosvetsky et al., 2016), and bio-oxidation of $\mathrm{H}_{2}$ resulted in high anodic dissolution rate of steel (Schutz et al., 2014, 2015). IRB induced corrosion-inhibition was always linked to a modification of the environmental conditions at the metal/solution interface by biological activity, i.e., formation of green rust or an iron (II) phosphate layer in biofilm contained IRB could prevent the corrosive agents from reaching steel surface (Duan et al., 2008; Cote et al., 2015). Based on above results, the mechanisms of IOB or IRB have been studied indepth, but the joint effects of IOB and IRB on metal corrosion are poorly known. It has been widely accepted that the redoxinduced cycling of iron is primarily controlled by combined effects of IOB and IRB in environment (Weber et al., 2006; Lee et al., 2013; Byrne et al., 2015). Investigators have found that the presence of mixed consortium (IOB and IRB) caused a measurable loss from the surface of carbon steel (Lee et al., 2013). However, the mechanism of mixed consortium induced carbon steel corrosion, i.e., surface morphology, corrosion products composition, environmental parameters and electrochemical behaviors, is relatively underexplored.

In this paper, the adsorptions of $\operatorname{IOB}(M . f$.), IRB ( $T$. sp.) and mixed consortium ( $M . f$. and T. sp.) on surface of Q235 carbon steel in seawater were investigated by scanning electron microscope (SEM) and energy dispersive spectrum (EDS). Environmental parameters and weight loss in different culture media were measured. Open circuit penitential (OCP) and electrochemical impedance spectroscopy (EIS) were applied to investigate electrochemical information. X-ray photoelectron spectroscopy (XPS) were used to study surface composition of Q235 carbon steel. Finally, the corrosion mechanism of mixed consortium induced corrosion of Q235 carbon steel in seawater was discussed.

\section{MATERIALS AND METHODS}

\section{Materials}

In this paper, Q235 carbon steel coupons with the shape of disk (10 $\mathrm{mm}$ diameter) were used for electrochemical measurements and surface analysis, and cut from Q235 carbon steel plate (wt. \%, 0.1 C, 0.4 Mn, 0.12 Si, 0.02 S, 0.05 P, and Fe balance). The Q235 carbon steel electrode were manufactured through embedding in a mold of non-conducting epoxy resin with $0.785 \mathrm{~cm}^{2}$ left exposed. Prior to each experiment, the exposed surfaces of all coupons were sequentially polished with a series of mesh silicon carbide emery papers $(400,800,1200$, and 2000) to smoothen. They were then rinsed with deionized water, degreased with absolute ethyl alcohol, and dried with pure nitrogen (>99.99\%). Finally, all the coupons were sterilized by exposing to ultraviolet radiation for $30 \mathrm{~min}$.

\section{Bacterial Culture}

Iron-oxidizing bacteria, i.e., M. $f$. (ATCC BAA-1020), were purchased from American Type Culture Collection (ATCC). IRB, i.e., T. sp., were isolated from marine sludge collected from South China Sea through a selective culture medium, which is contained (g/L, natural seawater): $0.5 \mathrm{~g} \mathrm{KH}_{2} \mathrm{PO}_{4}, 0.5 \mathrm{~g} \mathrm{Na}_{3} \mathrm{NO}_{3}$,

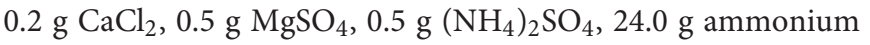
ferric citrate. In order to create a same system for further tests, M. f., T. sp., and mixed consortium were cultivated using a same medium. This was prepared by the following procedures: a medium contained (per $1 \mathrm{~L}$ seawater) $1 \mathrm{~g} \mathrm{NH}_{4} \mathrm{Cl}, 0.5 \mathrm{~g}$ $\mathrm{K}_{2} \mathrm{HPO}_{4}, 3 \mathrm{~g} \mathrm{Na}_{3} \mathrm{C}_{6} \mathrm{H}_{6} \mathrm{O}_{7} \cdot 2 \mathrm{H}_{2} \mathrm{O}$, and $0.84 \mathrm{~g} \mathrm{NaHCO}_{3}$ was autoclaved at $121^{\circ} \mathrm{C}$ for $20 \mathrm{~min}$. After cooling down in air to ambient temperature, the $\mathrm{pH}$ value of culture medium was adjusted to $7.0 \pm 0.1$ using $1 \mathrm{M} \mathrm{NaOH}$ or $\mathrm{HCl}$ solution. $1 \mathrm{~mL}$ Wolf vitamin and trace elements was added in culture medium through $0.2 \mu \mathrm{m}$ millipore filter, and then the sterilized Q235 carbon steel coupons were added to culture medium under aseptic condition. In this work, because $M . f$. and $T$. sp. were microaerophilic and facultative anaerobic microbes, respectively, the DO concentration was adjusted to $2.4 \pm 0.1 \mathrm{mg} / \mathrm{L}$ through pumping into pure nitrogen $(>99.99 \%)$ to ensure the survival of these two bacteria. Finally, the culture medium inoculated with M. f., T. sp., or mixed consortium was cultivated in an electric thermostat box (MJX-280, Ningbo Jiangnan Instrument Factory) at $30^{\circ} \mathrm{C}$. In culture medium, $\mathrm{Na}_{3} \mathrm{C}_{6} \mathrm{H}_{6} \mathrm{O}_{7} \cdot 2 \mathrm{H}_{2} \mathrm{O}$ and corrosion products of Q235 carbon steel served as carbon and iron sources, respectively, for the bacterial growth.

\section{Environmental Parameter and Weight Loss Measurement}

The environment parameter, weight loss and electrochemical tests were performed in a $500 \mathrm{ml}$ wild-mouth bottle with $400 \mathrm{ml}$ media. Concentration of dissolved oxygen (DO) and $\mathrm{pH}$ in $M$. $f$., $T$. sp. or mixed consortium media for different times were detected everyday by a dissolved oxygen meter (Thermo Orion 5Star; Thermo Fisher Scientific Inc., Massachusetts, United States) and a $\mathrm{pH}$ meter (PHS-3C; INESA Scientific Instruments Co., Ltd., Shanghai, China), respectively. The weight loss of each 
coupon was obtained by a XSE analytical balance (METTLER TOLEDO, $0.01 \mathrm{mg} / 0.1 \mathrm{mg}$ ). At different duration time, three coupons were taken out and cleaned according to the standard of ASTM G1-2003.

\section{Electrochemical Experiments}

Open circuit penitential and EIS were measured by using CHI 604D (CH Instruments, Inc.) electrochemical workstation in a three-electrode system. Q235 carbon steel, graphite sheet (surface area is about $4.91 \mathrm{~cm}^{2}$ ), and $\mathrm{Ag} / \mathrm{AgCl}$ electrode are working, counter and reference electrodes, respectively. Each impedance spectrum was measured at OCP under excitation of a sinusoidal wave with an amplitude of $5 \mathrm{mV}$, and within a frequency range of $1 \times 10^{5}$ to $1 \times 10^{-2} \mathrm{~Hz}$. The results of EIS were analyzed by Zsimpwin software. All electrochemical experiments were conducted at $25 \pm 2^{\circ} \mathrm{C}$.

\section{Surface and Component Analysis}

The micromorphology of Q235 carbon steel surface was obtained by using a SEM (Hitachi S-3400N), and the elemental distribution of carbon was obtained through the coupled EDS. Before observation, coupons were first fixed with $2.5 \%$ glutaraldehyde in a phosphate buffer solution ( $\mathrm{pH}$ 7.3-7.4) for $2 \mathrm{~h}$, washed with phosphate buffer solution for three times, rinsed with deionized water for another three times, and then dehydrated with using an ethanol gradient (30, 50, 70, 90, and 100 vol. \% for 15 min each). Finally, they were supercritically dried, and coated with gold.

Chemical composition information of Q235 carbon steel in M. f., T. sp., and mixed consortium media for 11 days was obtained by XPS (Thermo Fisher Scientific ESCALAB 250, $\mathrm{Al} \mathrm{K} \alpha$ radiation). The high-resolution spectra were analyzed through a deconvolution fitting procedure using the XPS PeakFit 4.1 software.

\section{RESULTS AND DISCUSSION}

\section{Effects of Bacteria on Environmental Parameters}

Figure 1 shows the evolution of $\mathrm{pH}$ and $\mathrm{DO}$ concentration in sterile, $M . f$., $T$. sp., and mixed consortium media along with time. As shown in Figure 1A, pH in sterile medium keeps stable at seven for different times. The evolution of $\mathrm{pH}$ in M.f., T. sp., and mixed consortium media shows different trends along with time. In M.f. medium, $\mathrm{pH}$ decreases and then keeps stable at 6.4 along with time, which may be due to that $\mathrm{Fe}^{3+}$ produced from the metabolism of $M$. $f$. reacts with $\mathrm{H}_{2} \mathrm{O}$ to form insoluble $\mathrm{Fe}(\mathrm{OH})_{3}$ and $\mathrm{H}^{+}$(Weber et al., 2006). However, in T. sp. medium, $\mathrm{pH}$ increases and then keeps stable at 7.4 along with time, which may be due to that $\mathrm{Fe}^{3+}$ oxides are reduced by $T$. sp., and $\mathrm{OH}^{-}$as byproducts is formed. In mixed consortium medium, $\mathrm{pH}$ decreases slightly, and then keeps stable at 6.8 , indicating that $\mathrm{pH}$ is mainly affected by the presence of $M$. $f$.

The evolution of DO concentration in different culture media also shows different trends along with time. In sterile and $M$. $f$. media, concentration of DO slightly decreases and then keeps stable at 2.37 and $2.25 \mathrm{mg} / \mathrm{L}$, respectively (Figure $\mathbf{1 B}$ ). This is due to that corrosion of carbon steel consumes little oxygen in sterile medium, and the metabolism of microaerophilic $M$. $f$. results in lower concentration of DO than that in sterile medium. However, in T. sp. and mixed consortium media, DO concentration remarkably decreases and then keeps stable at $0.4 \mathrm{mg} / \mathrm{L}$ along with time, which may be due to that the facultative $T$. sp. consume the oxygen in culture medium. These behaviors indicate that DO concentration in mixed consortium medium is mainly affected by the presence of $T$. sp.

\section{Analysis of OCP and Weight Loss of Q235 Carbon Steel}

Figure 2 shows the evolution of OCP and weight loss of Q235 carbon steel in different media along with time. As shown in Figure 2A, there are different evolution trends for the OCP in sterile, $M . f$., $T$. sp., and mixed consortium media. In sterile and M. f. media, OCP increases to -0.49 and $-0.42 \mathrm{~V}$, respectively, after 11 days of exposure. However, in T. sp. and mixed consortium media, OCP decreases with time, and to -0.57 and $-0.54 \mathrm{~V}$, respectively, after 11 days of exposure. These behaviors indicate that the evolution of OCP of Q235 carbon steel in mixed consortium medium is closely related with the presence of $T$. sp. In $M . f$., T. sp., and mixed consortium media, the average weight loss is larger than that in sterile medium after 1 day of exposure, indicating that the presence of bacteria promotes the corrosion of Q235 carbon steel (Figure 2B). Additionally, the average weight loss $(\mathrm{WL})$ in different culture media increases in the order: $W L_{\text {sterile }}<W L_{T \text {. sp. }}<W L_{\text {mixedconsortium }}<W L_{M . f}$. after 2 days of exposure, especially on the 11th day of exposure, the average weight loss in sterile, T. sp., mixed consortium, and M. f. media is $2.78,8.26,10.81$, and $13.69 \mathrm{mg} \mathrm{cm}^{-2}$, respectively (Figure $\mathbf{2 B}$ ). This indicates that corrosion rates of Q235 carbon steel in different culture media decrease in the order: $r_{M . f .}>r_{\text {mixedconsortium }}>r_{T \text {. sp. }}>r_{\text {sterile. }}$

\section{Analysis of EIS}

Figure 3 shows the EIS spectra of Q235 carbon steel in sterile, M. f., T. sp., and mixed consortium media along with time. As shown in Figure 3, a big capacitance arc and two wave peaks are observed in Nyquist and Bode plots, repectively, for Q235 carbon steel in different culture media for different time (Figure 3). These behaviors indicate the presence of two processes, i.e., electron transfer process and film adsorption, which control corrosion process. The diameters of capacitive arcs in bacterial medium are smaller than that in sterile medium. These behaviors indicate that corrosion of Q235 carbon steel is promoted due to the presence of bacteria.

Based on above analysis, the EIS in different media is fitted by using an equivalent circuit contained two time-constants, as shown in Figure 4. In the equivalent circuit, $Q$ is constant phase element (CPE) and given by:

$$
\mathrm{Z}_{C P E}=\frac{1}{Y_{0}(j \omega)^{n}}
$$



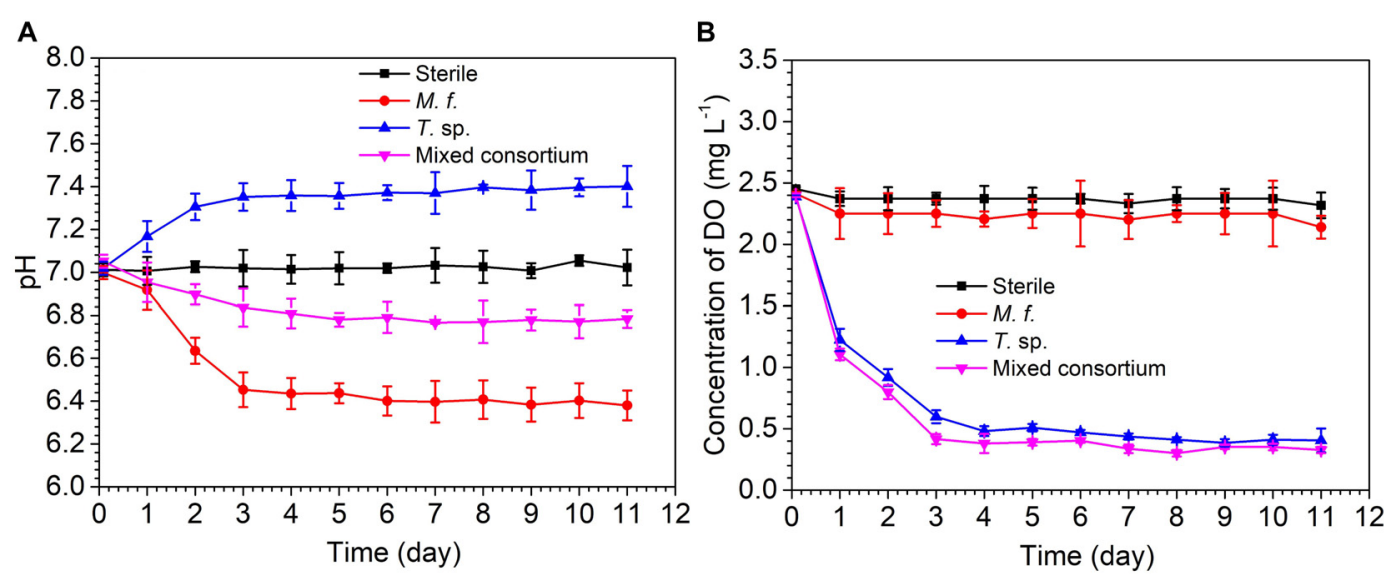

FIGURE 1 | The evolution of (A) pH and (B) concentration of dissolve oxygen in sterile, M. f., T. sp., and mixed consortium media along with time.
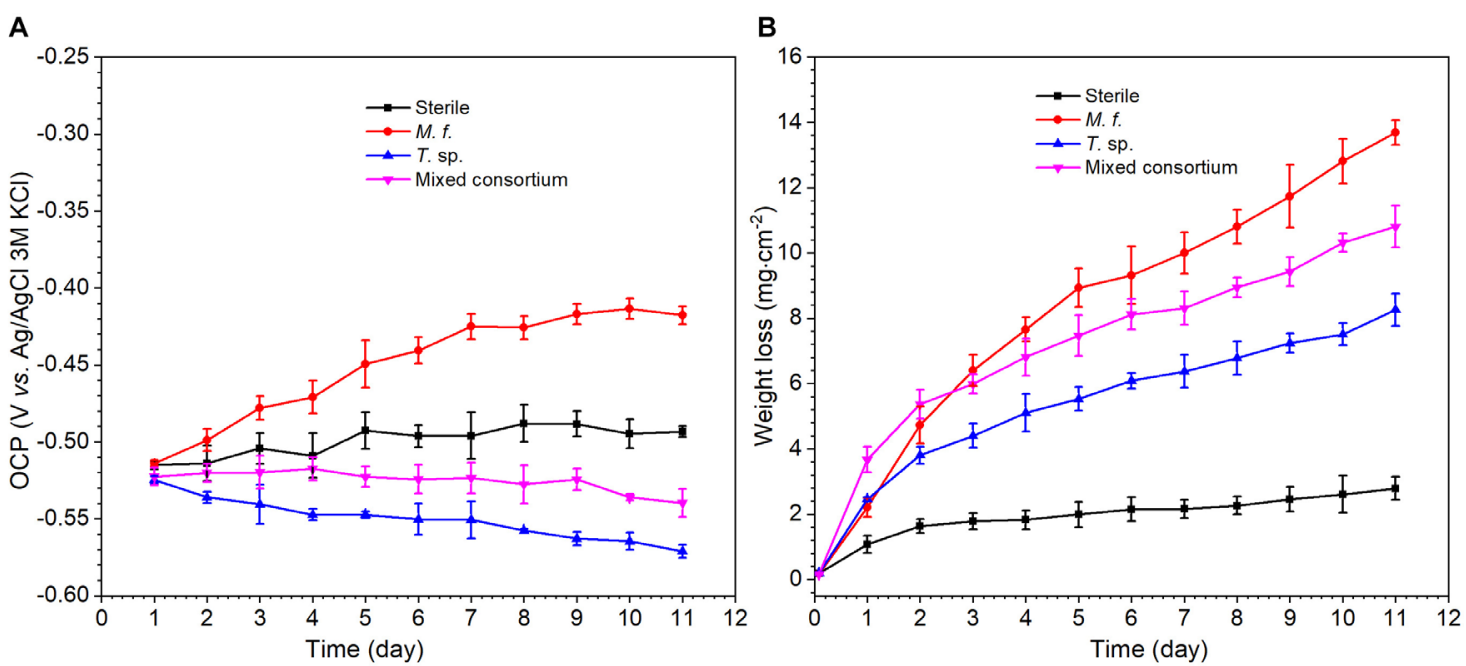

FIGURE 2 | The evolution of (A) OCP and (B) weight loss of Q235 carbon steel in sterile, M. f., T. sp., and mixed consortium media along with time.

where $Y_{0}$ is a parameter related to capacitance, $\omega$ is angular frequency, $j$ is imaginary number, and $n$ is exponential term related to roughness of electrode surface. $R_{\mathrm{s}}, R_{\mathrm{f}}$, and $R_{\mathrm{ct}}$ indicate resistances of electrolyte, surface film and charge transfer, respectively. $Q_{\mathrm{f}}$ and $Q_{\mathrm{dl}}$ are CPEs of surface film and electrical double layer, respectively. The fitting results in different media are listed in Table 1. As shown in Table 1, except for the 1st day of exposure, the value of $R_{\mathrm{ct}}$ in different culture media increases in the order: $R_{\mathrm{ct}}(M . f$. $)<R_{\mathrm{ct}}$ (mixed consortium) $<R_{\mathrm{ct}}(T$. sp.) $<R_{\mathrm{ct}}$ (sterile). These behaviors mean that corrosion of carbon steel in bacterial media, i.e., $M . f$., T. sp. and mixed consortium media, is promoted, and corrosion rate is biggest in M. f. medium after 1 day of exposure. Along with immersion time, the value of $R_{\mathrm{ct}}$ in sterile, T. sp., and mixed consortium media increases with time, while in $M . f$. medium decreases with time. These behaviors indicate that corrosion is inhibited in sterile medium along with the immersion time, which may be due to the accumulation of corrosion products on carbon steel surface. This agrees with the results of weight loss (Figure 2B). The corrosion rate decreases along with time (Table 1), and the OCP shifts to negative direction with time in both $T$. sp. and mixed consortium media (Figure 2A). This indicates that cathodic reaction process is inhibited, which may be due to the decrease of DO concentration in $T$. sp. and mixed consortium media (Figure 1B). Corrosion is promoted along with immersion time, and the OCP shifts to positive direction with time in $M . f$. medium (Figure 2). This means that cathodic reaction process is promoted, which may be due to the decrease of $\mathrm{pH}$, and the high concentration of DO in M. $f$. medium (Figure 1). From the above results, the evolution of corrosion rate of Q235 carbon steel in mixed consortium medium is mainly influenced by the presence of $T$. sp.

\section{Analysis of Micromorphology}

Figures 5-8 show the surface micromorphology of Q235 carbon steel in different media for 11 days. As shown in Figure 5, 

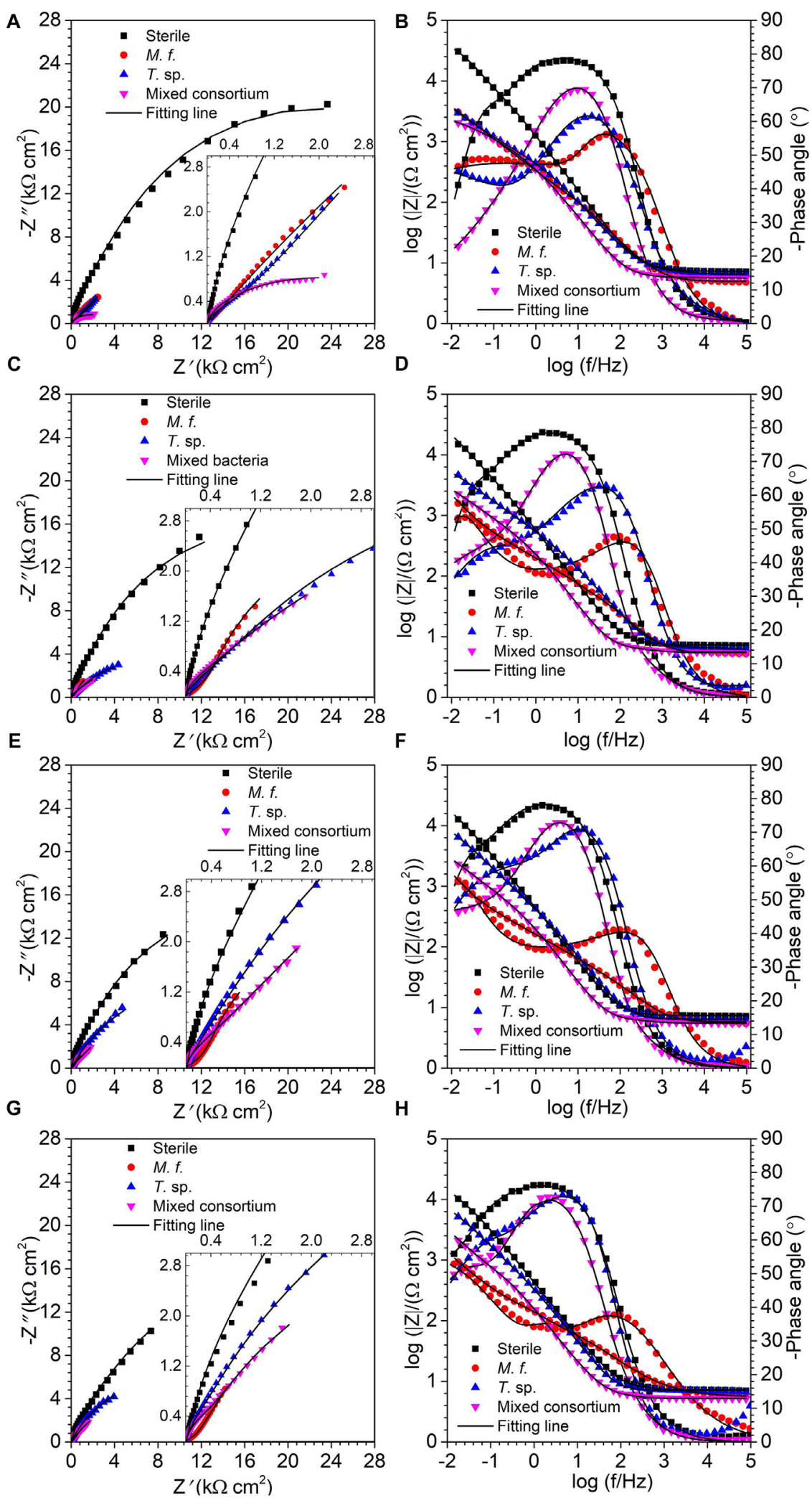

FIGURE 3 | EIS, (A,C,E,G) Nyquist and (B,D,F,H) Bode plots, of Q235 carbon steel in sterile, M. f., T. sp., and mixed consortium media for (A,B) 1, (C,D) 4, (E,F) 7 , and $\mathbf{( G , H )} 11$ days. 


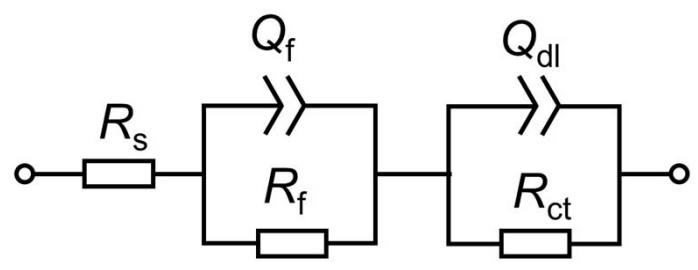

FIGURE 4 | The equivalent circuit model used to fit the EIS data in Figure 3.

a compact film adheres on surface of Q235 carbon steel after 11 days of exposure, and after removing corrosion products, uniform corrosion is the main corrosion form. Based on the results in Figure 3, this compact film protects the Q235 carbon steel in sterile medium. In $M . f$. medium, the morphology of Q235 carbon steel is obviously different with that in sterile medium, i.e., a huge local cluster coupled with some smaller ones is observed (Figure 6A), some bacterial cells adhere around the cluster (Figure 6B), and EDS distribution map shows the presence of plenty of elemental carbon in the cluster (Figure 6D). These behaviors indicate that biofilm is the main component of these cluster, and heterogeneous distribution is the typical form for M.f. biofilm on Q235 carbon steel surface (Figures 6A,C,D). After removing the corrosion products and biofilm, several pits are observed (Figure 6E), indicating pitting corrosion is the main form for Q235 carbon steel in $M$. $f$. medium. In T. sp. medium, surface morphology is uniform, and lot of granular corrosion products adhere onto the surface of Q235 carbon steel (Figure 7A). After removing the corrosion products, there are many very small pits on surface of Q235 carbon steel (Figure 7B), indicating that uniform corrosion is the main form for Q235 carbon steel in T. sp. medium. In mixed consortium medium, the surface morphology is similar with that in $M . f$. medium, i.e., there are some local clusters on surface of Q235

TABLE 1 | The fitting parameter of EIS data of Q235 carbon steel in sterile, M. f., T. sp., and mixed consortium media for different times.

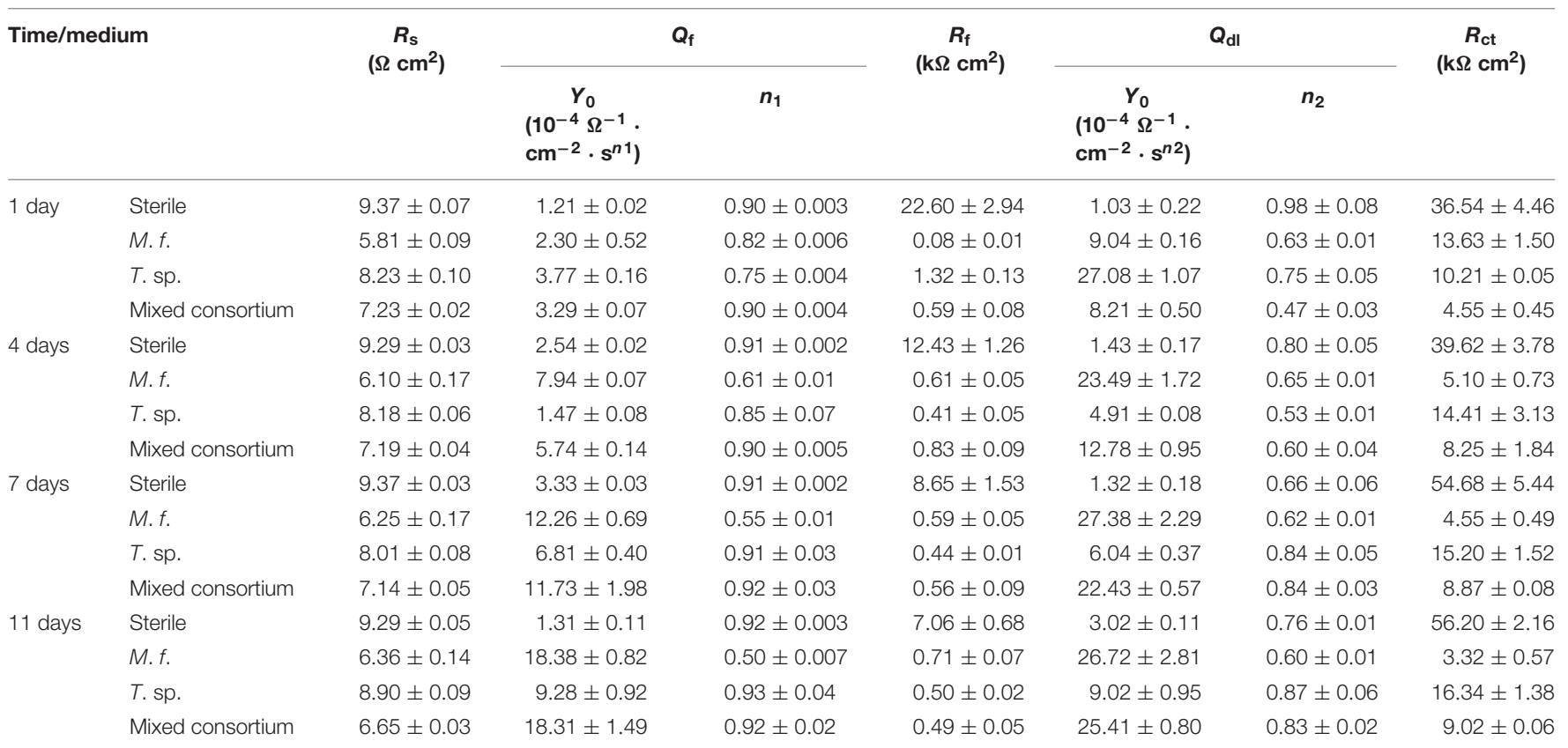

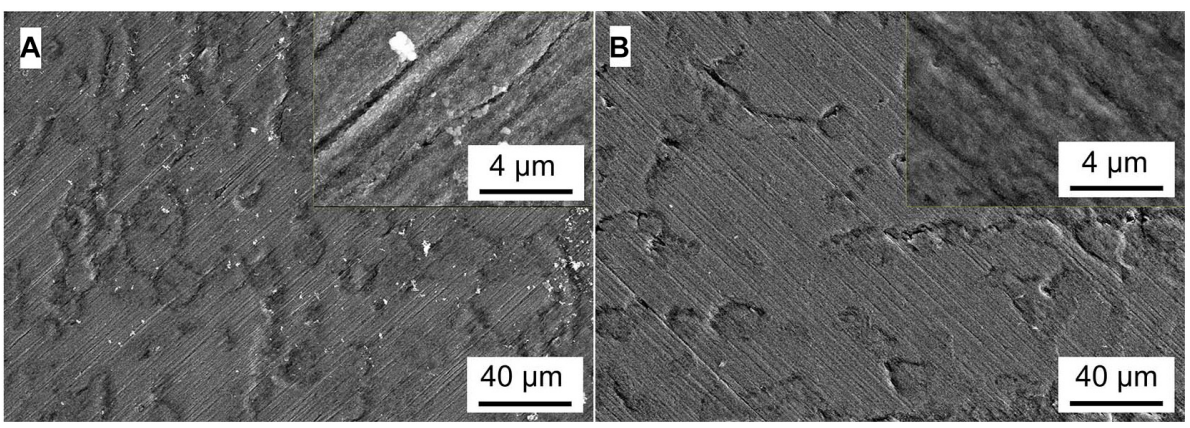

FIGURE 5 | SEM images of Q235 carbon steel (A) before and (B) after removing corrosion products film in sterile medium for 11 days. 


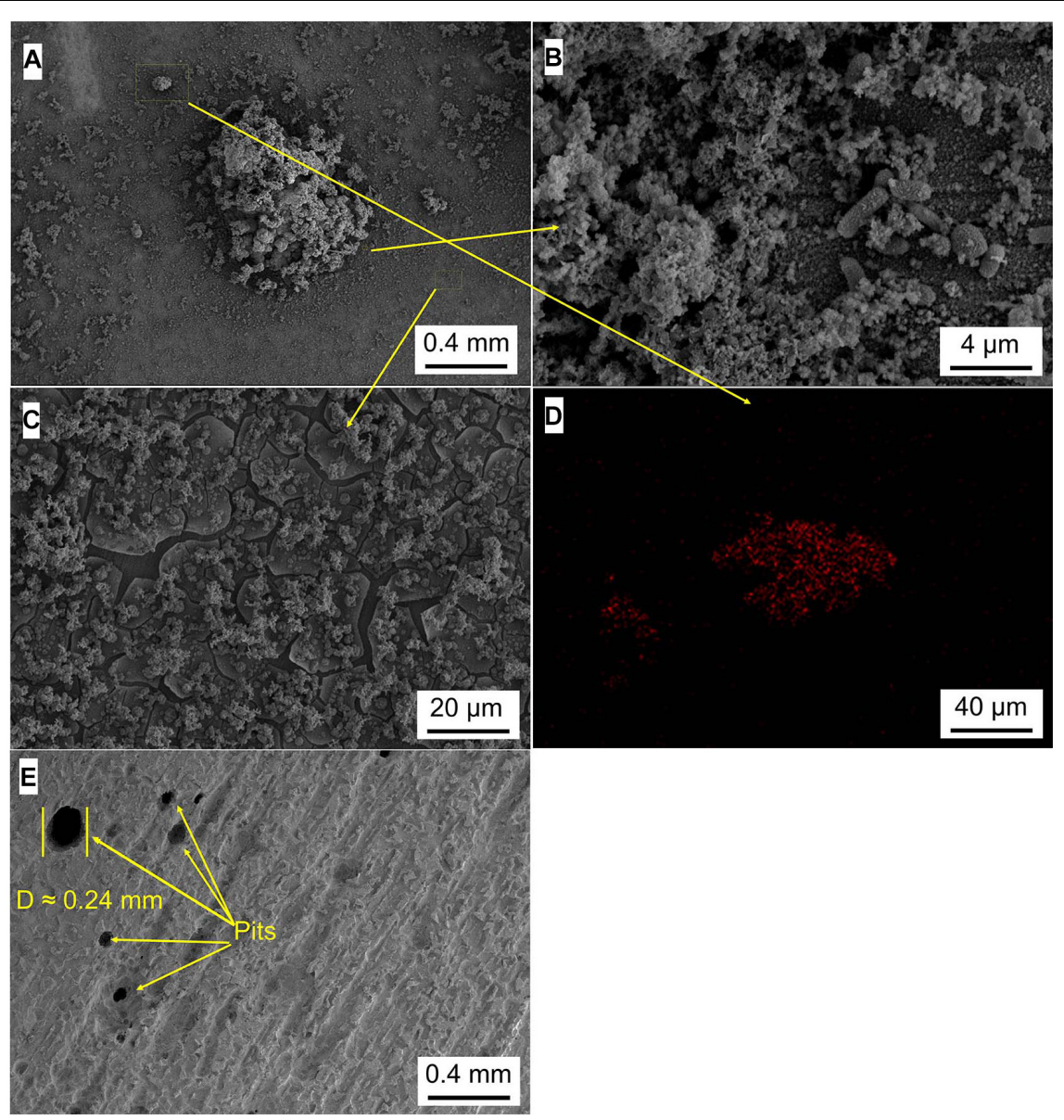

FIGURE 6 | SEM images of Q235 carbon steel (A-C) before and (E) after removing corrosion products film in M. $f$. medium for 11 days, and (D) elemental carbon distribution map.

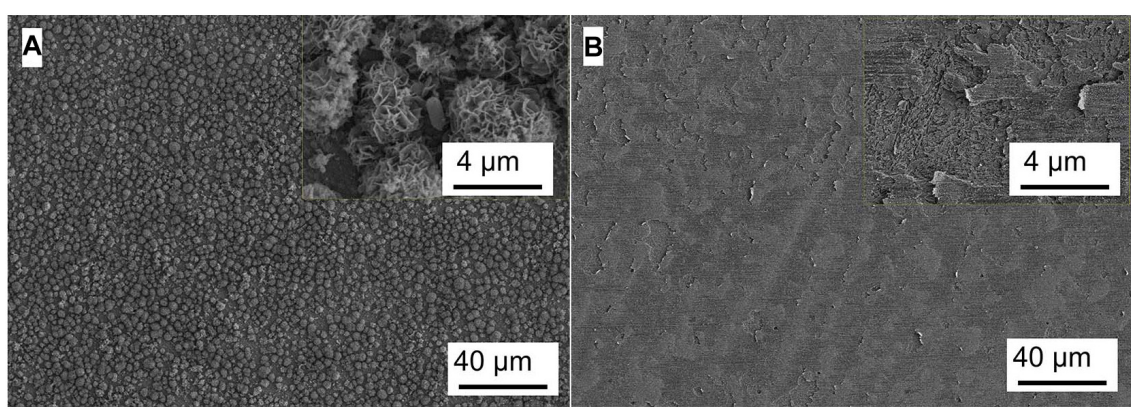

FIGURE 7 | SEM images of Q235 carbon steel (A) before and (B) after removing corrosion products film in $T$. sp. medium for 11 days.

carbon steel (Figure 8A), bacterial cells are observed in cluster (Figure 8C), and EDS distribution presents plenty of elemental carbon in these cluster (Figure 8D). These behaviors indicate that the main component of cluster is biofilm, and heterogeneous distribution is the typical form for the biofilm on Q235 carbon steel in mixed consortium medium (Figures 8A,B,D). After removing the corrosion products and biofilm, there are a lot of pits on surface of Q235 carbon steel (Figures 8E,F), meaning that localized corrosion is the main form for Q235 carbon steel in mixed consortium medium. These characteristics, i.e., morphology of biofilm and corrosion form, are similar with that in $M . f$. medium, but the degree of localized corrosion in mixed consortium medium is slighter than that in $M$. $f$. medium, i.e., the diameters of typical pits are 240 and $9.38 \mu \mathrm{m}$ in $M . f$. and mixed consortium media, respectively, and based on the statistic, the average diameters of pits are 105 and $8.79 \mu \mathrm{m}$ in $M . f$. and 


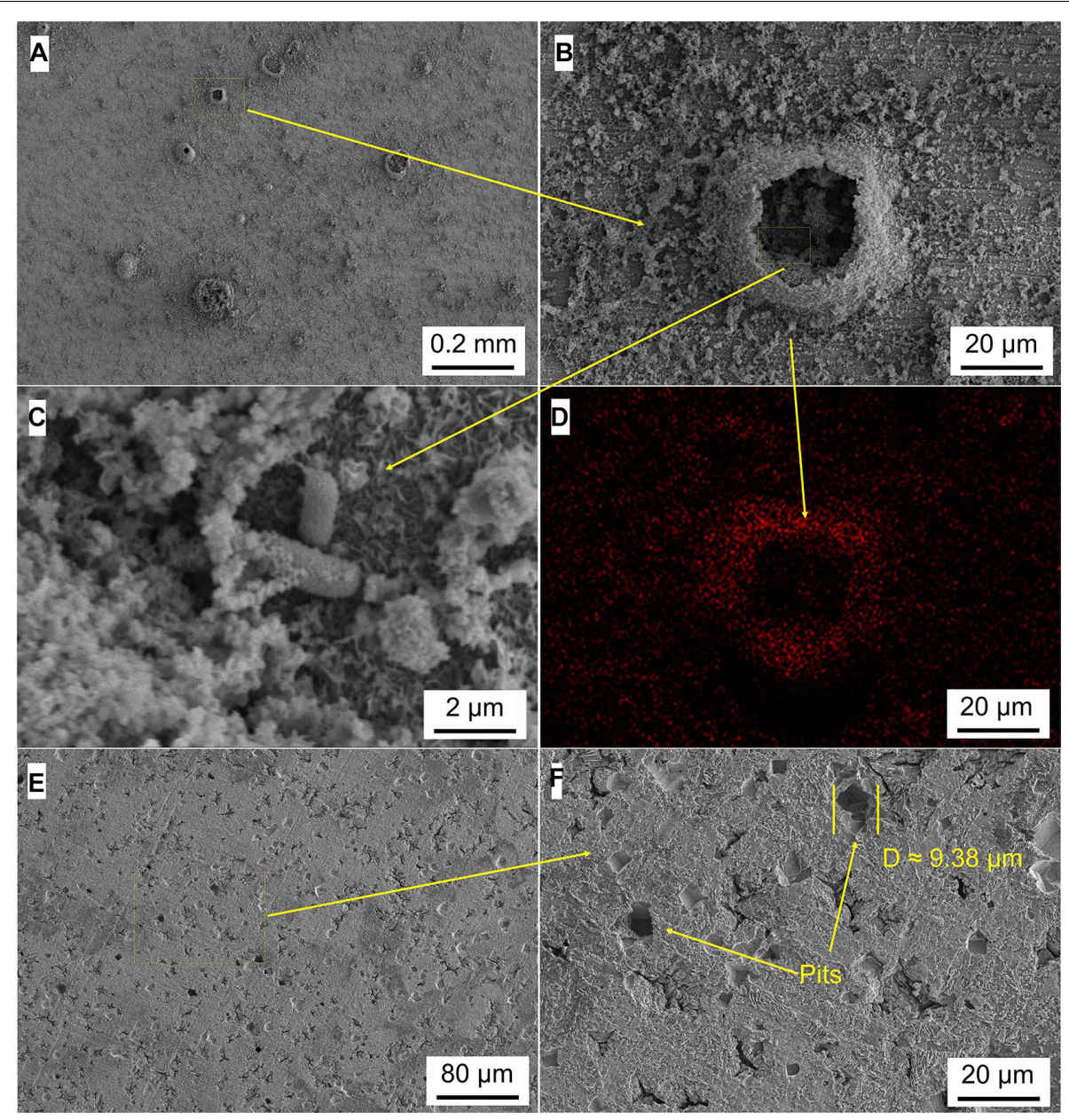

FIGURE 8 | SEM images of Q235 carbon steel (A-C) before and (E,F) after removing corrosion products film in mixed consortium medium for 11 days, and (D) elemental carbon distribution map.

mixed consortium media, respectively (Figures 6E, 8F). These behaviors indicate that biofilm morphology and corrosion form in mixed consortium medium are mainly affected by the presence of $M . f$., and the introduction of T. sp. inhibits the corrosion rate of localized corrosion of Q235 carbon steel.

\section{Analysis of XPS}

Figure 9 shows the survey spectra of Q235 carbon steel in sterile, M.f., T. sp., and mixed consortium media for 11 days. As shown in Figure 9, in all media, the following elements dominate on surface of Q235 carbon steel: Fe, C, O, N, Si, Ca, and Mn. In sterile medium, elemental $\mathrm{C}$ and $\mathrm{N}$ are mainly derived from the adsorption of organic substances from culture medium, and in bacterial media, i.e., M. f., T. sp., and mixed consortium media, mainly belonged to the biofilm. Elemental Si and $\mathrm{Ca}$ are from the culture medium, and elemental $\mathrm{Mn}$ is from the alloying element of Q235 carbon steel.

Figure 10 presents the fitting results of $\mathrm{Fe} 2 \mathrm{p}_{3 / 2}$ of Q235 carbon steel in sterile, M.f., T. sp., and mixed consortium media

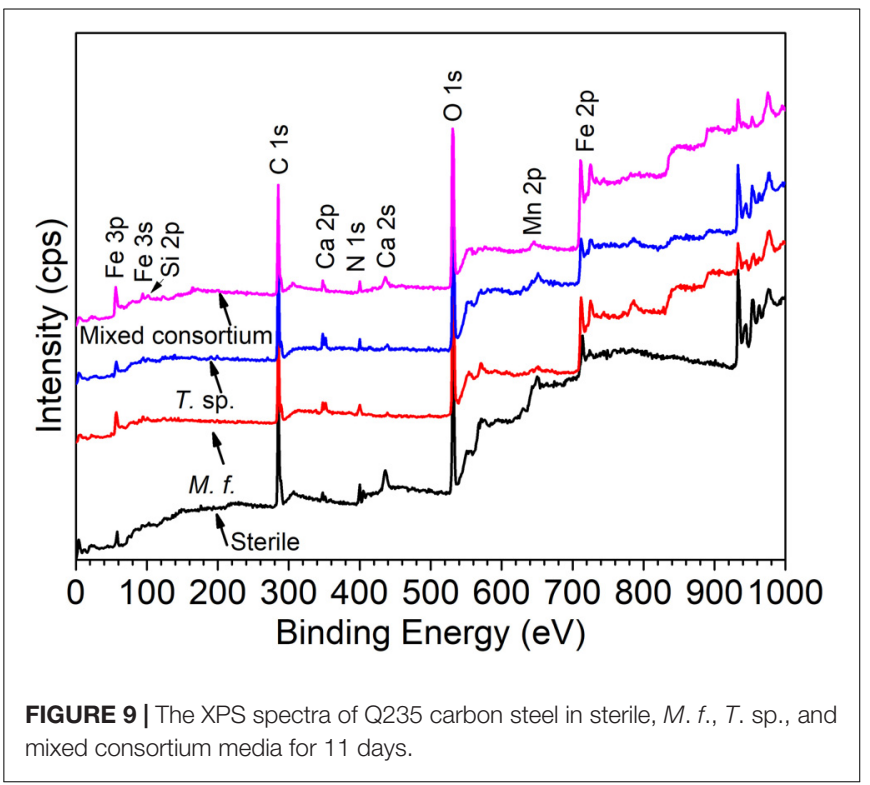


A

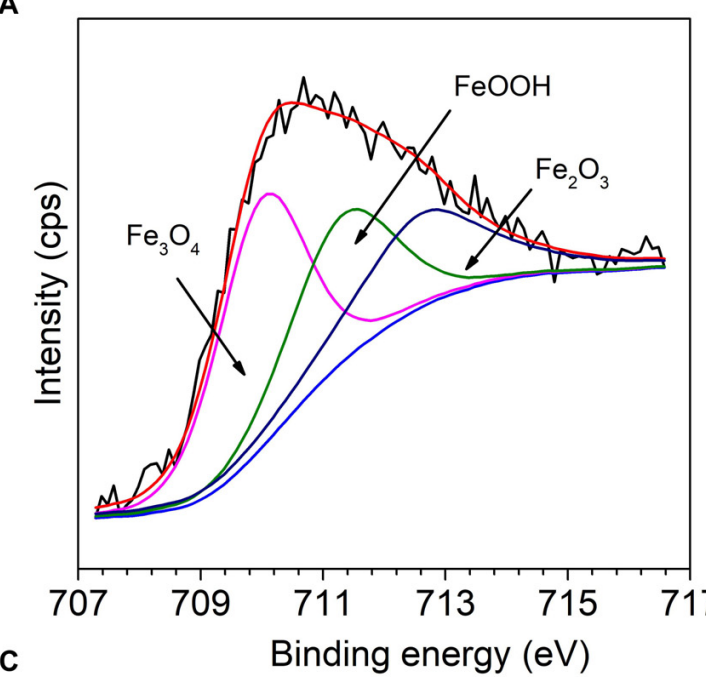

B

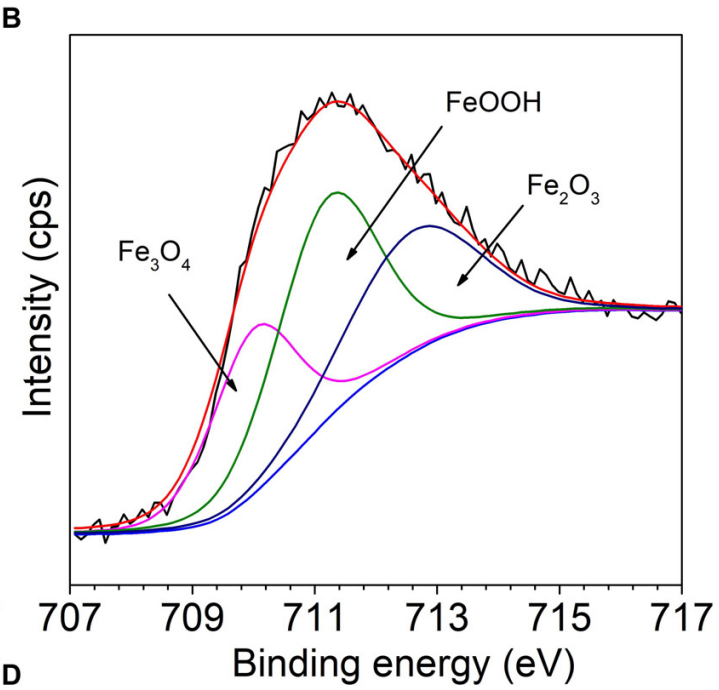

D

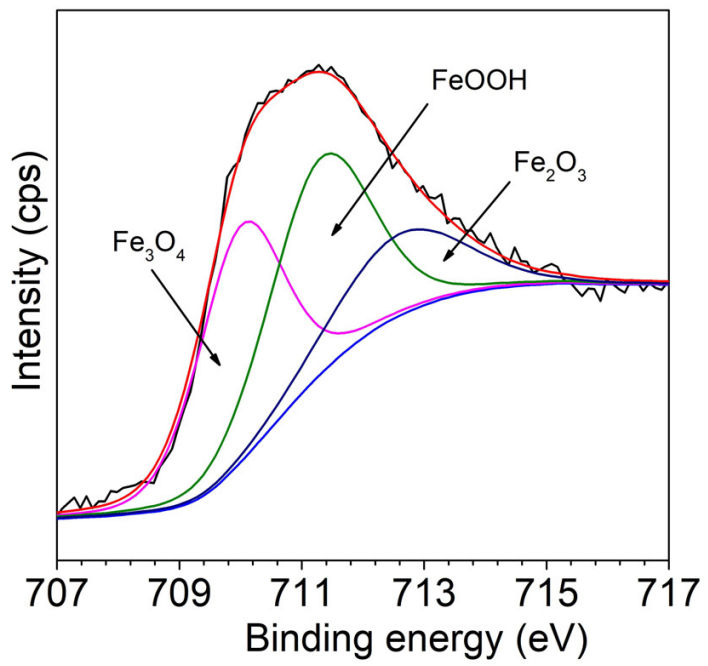

FIGURE 10 | The Fe 2p $\mathrm{p}_{3 / 2}$ high resolution spectra of Q235 carbon steel in (A) sterile, (B) M. f., (C) T. sp., and (D) mixed consortium media for 11 days.

for 11 days. The deconvolutions of all Fe 2 $\mathrm{p}_{3 / 2}$ spectra of Q235 carbon steel in sterile, M.f., T. sp., and mixed consortium media are fitted into three peaks (Figures 10A-D), i.e., the positions of the peaks are at $710.15 \mathrm{eV}, 711.5 \mathrm{eV}$, and $712.8 \mathrm{eV}$, which are attributed to $\mathrm{Fe}_{3} \mathrm{O}_{4}, \mathrm{FeOOH}$, and $\mathrm{Fe}_{2} \mathrm{O}_{3}$, respectively (Qi et al., 2016; Refait et al., 2016; Blackwood et al., 2017). Obviously, Fe oxides are the main components of corrosion products for Q235 carbon steel, which are same with each other in different media. Thus, it can be inferred that a series of subsequent reactions can occur in mixed consortium medium and generate $\mathrm{FeOOH}$, $\mathrm{Fe}_{2} \mathrm{O}_{3}$, and $\mathrm{Fe}_{2} \mathrm{O}_{3}$ :

$$
\begin{gathered}
\mathrm{Fe} \rightarrow \mathrm{Fe}^{2+}+2 e \\
\mathrm{Fe}^{2+} \underset{I R B}{\stackrel{I O B}{\rightleftarrows}} \mathrm{Fe}^{3+} \\
\mathrm{Fe}^{3+}+2 \mathrm{H}_{2} \mathrm{O} \rightarrow \mathrm{FOOH}+3 \mathrm{H}^{+}
\end{gathered}
$$

$$
\begin{gathered}
2 \mathrm{FOOH}+\mathrm{Fe}^{2+} \rightarrow \mathrm{Fe}_{3} \mathrm{O}_{4}+2 \mathrm{H}^{+} \\
\mathrm{Fe}_{3} \mathrm{O}_{4} \underset{I R B}{\stackrel{I O B}{\rightleftarrows}} \mathrm{Fe}_{2} \mathrm{O}_{3}
\end{gathered}
$$

The relative content (RC) of corrosion products components in different media is further analyzed, and the results are listed in Table 2. As shown in Table 2, the RCs of FeOOH

TABLE 2 | The RC of components of corrosion products on surface of Q235 carbon steel in sterile, M. f., T. sp., and mixed consortium media for 11 days.

\begin{tabular}{lccccc}
\hline $\begin{array}{l}\text { Components of } \\
\text { corrosion products }\end{array}$ & $\begin{array}{c}\text { Position } \\
\text { (eV) }\end{array}$ & $\begin{array}{c}\text { Sterile } \\
\text { (At. \%) }\end{array}$ & $\begin{array}{c}\text { M. f. } \\
\text { (At. \%) }\end{array}$ & $\begin{array}{c}\text { T. sp. } \\
\text { (At. \%) }\end{array}$ & $\begin{array}{c}\text { Mixed } \\
\text { consortium } \\
\text { (At. \%) }\end{array}$ \\
\hline $\mathrm{Fe}_{3} \mathrm{O}_{4}$ & 710.15 & 42 & 27 & 66 & 38 \\
$\mathrm{FeOOH}$ & 711.5 & 29 & 43 & 18 & 41 \\
$\mathrm{Fe}_{2} \mathrm{O}_{3}$ & 712.8 & 29 & 30 & 16 & 21
\end{tabular}




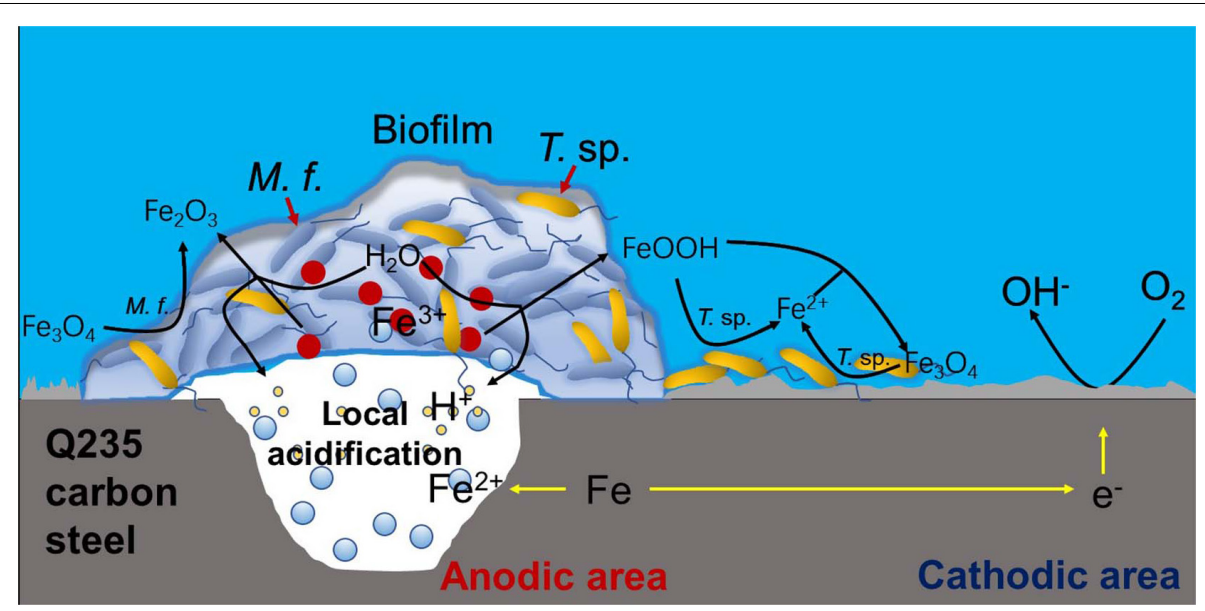

FIGURE 11 | The corrosion mechanism model of Q235 carbon steel in mixed consortium medium.

and $\mathrm{Fe}_{2} \mathrm{O}_{3}$ in different media decreases in the order: $\mathrm{RC}_{M}$.f. $(73 \%)>\mathrm{RC}_{\text {mixedconsortium }}(62 \%)>\mathrm{RC}_{\text {sterile }}(58 \%)>\mathrm{RC}_{T}$. sp. (34\%), and the order of $\mathrm{RC}$ of $\mathrm{Fe}_{3} \mathrm{O}_{4}$ is reversed with that of $\mathrm{FeOOH}$ and $\mathrm{Fe}_{2} \mathrm{O}_{3}$, i.e., $\mathrm{RC}_{T}$. sp. $(66 \%)>\mathrm{RC}_{\text {sterile }}$ $(42 \%)>\mathrm{RC}_{\text {mixedconsortium }}(38 \%)>\mathrm{RC}_{M}$.f. $(27 \%)$. This indicates that the $\mathrm{RCs}$ of $\mathrm{Fe}^{3+}$ and $\mathrm{Fe}^{2+}$ in corrosion products are the biggest in $M . f$. and T. sp. media, respectively. This is derived from the metabolism of bacteria, i.e., M. f. and T. sp. conduct iron oxidization and reduction, respectively. In consortium medium, the RCs of $\mathrm{Fe}^{3+}$ and $\mathrm{Fe}^{2+}$ are between that in $M . f$. and T. sp. media, which indicates that RCs of components of corrosion products of Q235 carbon steel in mixed consortium are influenced by the presence of these two bacteria.

\section{Corrosion Mechanism Model}

Based on above analysis, a corrosion mechanism model of Q235 carbon steel in mixed consortium medium is proposed, as shown in Figure 11. It has been widely accepted that the heterogeneous adsorption of biofilm plays a significant role in localized corrosion process of metal (Zhong et al., 2016; Jia et al., 2017; Gu et al., 2019). Generally speaking, biofilms can be considered as living cells trapped in a heterogeneous matrix containing extracellular polymeric substances (EPS), adsorbed organic and inorganic substances, interspersed with interstitial voids (Dou et al., 2018). Biofilms with stratified structure are never uniform and have different thickness and coverage at different positions of the metal surface, as shown in Figures 6A, 8A. There are different trends for bacterial density, bacterial activity and dissolved oxygen concentration with different biofilm thicknesses (Guo et al., 2017; Liu T. et al., 2018; Liu et al., 2019). Additionally, metabolic activity of bacteria in biofilm makes chemical environment near metal surface much different from that in bulk solution, such as ion species, concentration, $\mathrm{pH}$, and oxygen level (Yuan and Pehkonen, 2007; Xu et al., 2013, 2016; Jia et al., 2018). These behaviors lead to electrochemical heterogeneity and induce or accelerate localized corrosion, as shown in Figures 6E, 8E,F. In
$M . f$. medium, the metabolism of $M . f$. results in the decrease of $\mathrm{pH}$ and local acidification under biofilm, and there is a higher concentration of DO out of biofilm (Figure 1). This provides an advantage for initiation and progress of pitting corrosion, i.e., electrochemical active sites under biofilm and support of enough cathodic reaction out of biofilm. In mixed consortium medium (Figure 11), the metabolism of $M . f$. also results in local acidification in the inside of biofilm, which creates electrochemical active sites on surface of Q235 carbon steel. However, on the outside of biofilm, the metabolism of $T$. sp. leads to the decrease of DO concentration, which inhibits cathodic reaction, and results in a slower localized corrosion rate than that in M.f. medium (Figures $6 \mathrm{E}, \mathbf{8 F}$ ). The corrosion products, i.e., $\mathrm{Fe}^{2+}$ ions, are oxidized to $\mathrm{Fe}^{3+}$ ions during the metabolism of $M$. $f$., which react with $\mathrm{H}_{2} \mathrm{O}$ to form ferric oxides and $\mathrm{H}^{+}$ions. Then, ferric oxides are used by $T$. sp. to form the $\mathrm{Fe}^{2+}$ ions, which react with $\mathrm{FeOOH}$ to produce magnetite $\left(\mathrm{Fe}_{3} \mathrm{O}_{4}\right)$ (Ishikawa et al., 2002). Meanwhile, magnetite can be oxidized and reduced by M. $f$. and T. sp. (Weber et al., 2006). Therefore, the both RCs of $\mathrm{Fe}^{3+}$ and $\mathrm{Fe}^{2+}$ in corrosion products of Q235 carbon steel are between that in M. $f$. and T. sp. media (Figure 10 and Table 2).

\section{CONCLUSION}

Corrosion of Q235 carbon steel is promoted in bacterial media due to the iron metabolism induced by $M . f_{.}, T$. sp., or mixed consortium. Corrosion rates of Q235 carbon steel in different culture media decrease in the order: $r_{M . f .}>r_{\text {mixedconsortium }}>r_{T \text {. sp. }}>r_{\text {sterile. }}$. The DO concentration decreases in both T. sp. and mixed consortium media, which results in the similar evolution of corrosion rate of Q235 carbon steel in these two media. Biofilm is locally adhered on Q235 carbon steel surface in both $M$. $f$. and mixed consortium media, which induces localized corrosion of Q235 carbon steel. Corrosion products components of Q235 carbon steel in mixed consortium medium are $\mathrm{Fe}_{3} \mathrm{O}_{4}, \mathrm{FeOOH}$ 
and $\mathrm{Fe}_{2} \mathrm{O}_{3}$, and their RCs are influenced by the presence of M.f. and T. sp.

\section{DATA AVAILABILITY}

All datasets generated for this study are included in the manuscript and/or the supplementary files.

\section{AUTHOR CONTRIBUTIONS}

SC performed the experiments and the data analysis, and drafted the main manuscript. HD collated the experimental data. DZ

\section{REFERENCES}

Bhandari, J., Khan, F., Abbassi, R., Garaniya, V., and Ojeda, R. (2015). Modelling of pitting corrosion in marine and offshore steel structures-A technical review. J. Loss Prevent. Proc. Ind. 37, 39-62. doi: 10.1016/j.jp.2015.06.008

Blackwood, D. J., Lim, C. S., and Teo, S. L. M. (2017). Macrofouling induced localized corrosion of stainless steel in Singapore seawater. Corros. Sci. 129, 152-160. doi: 10.1016/j.corsci.2017.10.008

Byrne, J. M., Klueglein, N., Pearce, C., Rosso, K. M., Appel, E., and Kappler, A. (2015). Redox cycling of Fe (II) and Fe (III) in magnetite by Fe-metabolizing bacteria. Science 347, 1473-1476. doi: 10.1126/science.aaa4834

Chen, S., and Zhang, D. (2019). Corrosion behavior of Q235 carbon steel in airsaturated seawater containing Thalassospira sp. Corros. Sci. 148, 71-82. doi: 10.1016/j.corsci.2018.11.031

Cote, C., Rosas, O., and Basseguy, R. (2015). Geobacter sulfurreducens : an iron reducing bacterium that can protect carbon steel against corrosion? Corros. Sci. 94, 104-113. doi: 10.1016/j.corsci.2015.01.044

Dou, W., Jia, R., Jin, P., Liu, J., Chen, S., and Gu, T. (2018). Investigation of the mechanism and characteristics of copper corrosion by sulfate reducing bacteria. Corros. Sci. 144, 237-248. doi: 10.1016/j.corsci.2018.08.055

Duan, J. Z., Wu, S. R., Zhang, X. J., Huang, G. Q., Du, M., and Hou, B. R. (2008). Corrosion of carbon steel influenced by anaerobic biofilm in natural seawater. Electrochim. Acta 54, 22-28. doi: 10.1016/j.electacta.2008.04.085

Esnault, L., Jullien, M., Mustin, C., Bildstein, O., and Libert, M. (2011). Metallic corrosion processes reactivation sustained by iron-reducing bacteria: implication on long-term stability of protective layers. Phys. Chem. Earth 36, 1624-1629. doi: 10.1016/j.pce.2011.10.018

Fortney, N. W., He, S., Converse, B. J., Boyd, E. S., and Roden, E. E. (2018). Investigating the composition and metabolic potential of microbial communities in chocolate pots hot springs. Front. Microbiol. 9:2075. doi: 10. 3389/fmicb.2018.02075

Gu, T., Jia, R., Unsal, T., and Xu, D. (2019). Toward a better understanding of microbiologically influenced corrosion cause by sulfate reducing bacteria. J. Mater. Sci. Technol. 35, 631-636. doi: 10.1016/j.jmst.2018.10.026

Guo, Z., Liu, T., Cheng, Y. F., Guo, N., and Yin, Y. (2017). Adhesion of Bacillus subtilis and Pseudoalteromonas lipolytica to steel in a seawater environment and their effects on corrosion. Colloid. Surface. B. 157, 157-165. doi: 10.1016/j. colsurfb.2017.05.045

Ishikawa, T., Kumagai, M., Yasukawa, A., Kandori, K., Nakayama, T., and Yuse, F. (2002). Influences of metal ions on the formation of $\gamma$-FeOOH and magnetite rusts. Corros. Sci. 44, 1073-1086. doi: 10.1016/S0010-938X(01) 00119-6

Jia, R., Tan, J. L., Jin, P., Blackwood, D. J., Xu, D., and Gu, T. (2018). Effects of biogenic $\mathrm{H}_{2} \mathrm{~S}$ on the microbiologically influenced corrosion of C1018 carbon steel by sulfate reducing Desulfovibrio vulgaris biofilm. Corros. Sci. 130, 1-11. doi: 10.1016/j.corsci.2017.10.023

Jia, R., Yang, D., Xu, J., Xu, D., and Gu, T. (2017). Microbiologically influenced corrosion of C1018 carbon steel by nitrate reducing Pseudomonas aeruginosa biofilm under organic carbon starvation. Corros. Sci. 127, 1-9. doi: 10.1016/j. corsci.2017.08.007 and GL provided the place for experiments and modified the manuscript. All authors read and approved the final manuscript.

\section{FUNDING}

This work was funded by the National Natural Science Foundation of China (51771180), the National Key Research and Development Program of China (2016YFB0300604 and 2014CB643304), and AoShan Talent Program Supported by Qingdao National Laboratory for Marine Science and Technology, the Fundamental Research Funds of Shandong University (62420078614131).

Lee, J. S., McBeth, J. M., Ray, R. I., Little, B. J., and Emerson, D. (2013). Iron cycling at corroding carbon steel surfaces. Biofouling. 2, 1243-1252. doi: 10. 1080/08927014.2013.836184

Li, X., Wang, H., Hu, X., Hu, C., and Liao, L. (2016). Characteristics of corrosion sales and biofilm in aged pipe distribution systems with switching water source. Eng. Fail. Anal. 60, 166-175. doi: 10.1016/j.engfailanal.2015.11.048

Liu, H., Cheng, Y., Xu, D., and Liu, H. (2018). Effect of iron oxidizing bacteria biofilm on corrosion inhibition of imidazoline derivative in $\mathrm{CO}_{2}$-containing oilfield produced water with organic carbon source starvation. J. Electrochem. Soc. 165, C354-C361. doi: 10.1149/2.0741807jes

Liu, H., Gu, T., Zhang, G., Cheng, Y., Wang, H., and Liu, H. (2016). The effect of magnetic field on biomineralization and corrosion behavior of carbon steel induced by iron-oxidizing bacteria. Corros. Sci. 102, 93-102. doi: 10.1016/j. corsci.2015.09.023

Liu, T., Guo, Z., Zeng, Z., Guo, N., Lei, Y., Liu, T., et al. (2018). Marine bacteria provide lasting anticorrosion activity for steel via biofilm-induced mineralization. ACS Appl. Mater. Inter. 10, 40317-40327. doi: 10.1021/acsami. 8 b14991

Liu, T., Wang, Y., Pan, S., Zhao, Q., Zhang, C., Gao, S., et al. (2019). The addition of copper accelerates the corrosion of steel via impeding biomineralized film formation of Bacillus subtilis in seawater. Corros. Sci. 149, 153-163. doi: 10. 1016/j.corsci.2019.01.010

McBeth, J. M., and Emerson, D. (2016). In situ microbial community succession on mild steel in estuarine and marine environments: exploring the role of iron-oxidizing bacteria. Front. Microbiol. 7:767. doi: 10.3389/fmicb.2016.00767

Mehanna, M., Basseguy, R., Delia, M. L., Girbal, L., Demuez, M., and Bergel, A. (2008). New hypotheses for hydrogenase implication in the corrosion of mild steel. Electrochim. Acta 54, 140-147. doi: 10.1016/j.electacta.2008.02.101

Pan, Y., Yang, X., Xu, M., and Sun, G. (2017). The role of enriched microbial consortium on iron-reducing bioaugmentation in sediments. Front. Microbiol. 8:462. doi: 10.3389/fmicb.2017.00462

Qi, Z., Lan, H., Joshi, T. P., Liu, R., Liu, H., and Qu, J. (2016). Enhanced oxidative and adsorptive capability towards antimony by copper-doping into magnetite magnetic particles. RSC Adv. 6, 66990-67001. doi: 10.1039/C6RA13412B

Qian, H., Zhang, D., Lou, Y., Li, Z., Xu, D., Du, C., et al. (2018). Laboratory investigation of microbiologically influenced corrosion of Q235 carbon steel by halophilic archaea Natronorubrum tibetense. Corros. Sci. 145, 151-161. doi: 10.1016/j.corsci.2018.09.020

Refait, P., Grolleau, A. M., Jeannin, M., François, E., and Sabot, R. (2016). Localized corrosion of carbon steel in marine media: galvanic coupling and heterogeneity of the corrosion product layer. Corros. Sci. 111, 583-595. doi: 10.1016/j.corsci. 2016.05.043

Schutz, M. K., Moreira, R., Bildstein, O., Lartigue, J. E., Schlegel, M. L., Tribollet, B., et al. (2014). Combined geochemical and electrochemical methodology to quantify corrosion of carbon steel by bacterial activity. Bioelectrochemist. 97, 61-68. doi: 10.1016/j.bioelechem.2013.07.003

Schutz, M. K., Schlegel, M. L., Libert, M., and Bildstein, O. (2015). Impact of iron-reducing bacteria on the corrosion rate of carbon steel under simulated geological disposal conditions. Environ. Sci. Techno. 49, 7483-7490. doi: 10. 1021 /acs.est.5b00693 
Starosvetsky, J., Kamari, R., Farber, Y., Bilanović, D., and Armon, R. (2016). Rust dissolution and removal by iron-reducing bacteria: a potential rehabilitation of rusted equipment. Corros. Sci. 102, 446-454. doi: 10.1016/j.corsci.2015.10.037

Starosvetsky, J., Starosvetsky, D., Pokroy, B., Hilel, T., and Armon, R. (2008). Electrochemical behaviour of stainless steels in media containing iron-oxidizing bacteria (IOB) by corrosion process modeling. Corros. Sci. 50, 540-547. doi: 10.1016/j.corsci.2007.07.008

Wang, H., Hu, C., Hu, X., Yang, M., and Qu, J. (2012). Effects of disinfectant and biofilm on the corrosion of cast iron pipes in a reclaimed water distribution system. Water Res. 46, 1070-1078. doi: 10.1016/j.watres.2011.12.001

Wang, H., Ju, L. K., Castaneda, H., Cheng, G., and Newby, B. M. Z. (2014). Corrosion of carbon steel $\mathrm{C} 1010$ in the presence of iron oxidizing bacteria Acidithiobacillus ferrooxidans. Corros. Sci. 89, 250-257. doi: 10.1016/j.corsci. 2014.09.005

Weber, K. A., Achenbach, L. A., and Coates, J. D. (2006). Microorganisms pumping iron: anaerobic microbial iron oxidation and reduction. Nat. Rev. Microbiol. 4, 752-764. doi: 10.1038/nrmicro1490

Xu, C., Zhang, Y., Cheng, G., and Zhu, W. (2007). Localized corrosion behavior of $316 \mathrm{~L}$ stainless steel in the presence of sulfate-reducing and iron-oxidizing bacteria. Mat. Sci. Eng. A. 443, 235-241. doi: 10.1016/j.msea.2006.08.110

$\mathrm{Xu}, \mathrm{D} ., \mathrm{Li}, \mathrm{Y}$., and Gu, T. (2016). Mechanistic modeling of biocorrosion caused by biofilms of sulfate reducing bacteria and acid producing bacteria. Bioelectrochemistry. 110, 52-58. doi: 10.1016/j.bioelechem.2016.03.003
Xu, D., Li, Y., Song, F., and Gu, T. (2013). Laboratory investigation of microbiologically influenced corrosion of C1018 carbon steel by nitrate reducing bacterium Bacillus licheniformis. Corros. Sci. 77, 385-390. doi: 10. 1016/j.corsci.2013.07.044

Yuan, S. J., and Pehkonen, S. O. (2007). Microbiologically influenced corrosion of 304 stainless steel by aerobic Pseudomonas NCIMB 2021 bacteria: AFM and XPS study. Colloid. Surface. B. 59, 87-99. doi: 10.1016/j.colsurfb.2007. 04.020

Zhong, H., Wang, J., Meng, F., and Zhang, X. (2016). In situ activating ubiquitous rust towards low-cost, efficient, free-standing, and recoverable oxygen evolution electrodes. Angew. Chem. Int. Edi. 128, 10091-10095. doi: 10.1002/anie. 201604040

Conflict of Interest Statement: The authors declare that the research was conducted in the absence of any commercial or financial relationships that could be construed as a potential conflict of interest.

Copyright (c) 2019 Chen, Deng, Liu and Zhang. This is an open-access article distributed under the terms of the Creative Commons Attribution License (CC BY). The use, distribution or reproduction in other forums is permitted, provided the original author(s) and the copyright owner(s) are credited and that the original publication in this journal is cited, in accordance with accepted academic practice. No use, distribution or reproduction is permitted which does not comply with these terms. 